\title{
Medium-Chain Acyl Coenzyme A Dehydrogenase from Pig Kidney Has Intrinsic Enoyl Coenzyme A Hydratase Activity ${ }^{\dagger}$
}

\author{
Sze-Mei Lau, ${ }^{\ddagger}$ Pat Powell, ${ }^{\ddagger}$ Hermann Buettner,${ }^{\S}$ Sandro Ghisla, ${ }^{\S}$ and Colin Thorpe ${ }^{*, \ddagger}$ \\ Chemistry Department, University of Delaware, Newark, Delaware 19716, and Fakultät für Biologie, Universität Konstanz, \\ D7750 Konstanz, West Germany
}

\begin{abstract}
The flavoprotein medium-chain acyl coenzyme A (acyl-CoA) dehydrogenase from pig kidney exhibits an intrinsic hydratase activity toward crotonyl-CoA yielding L-3-hydroxybutyryl-CoA. The maximal turnover number of about $0.5 \mathrm{~min}^{-1}$ is 500-1000-fold slower than the dehydrogenation of butyryl-CoA using electron-transferring flavoprotein as terminal acceptor. trans-2-Octenoyl- and trans-2-hexadecenoyl-CoA are not hydrated significantly. Hydration is not due to contamination with the short-chain enoyl-CoA hydratase crotonase. Several lines of evidence suggest that hydration and dehydrogenation reactions probably utilize the same active site. These two activities are coordinately inhibited by 2-octynoyl-CoA and (methylenecyclopropyl)acetyl-CoA [whose targets are the protein and flavin adenine dinucleotide (FAD) moieties of the dehydrogenase, respectively]. The hydration of crotonyl-CoA is severely inhibited by octanoyl-CoA, a good substrate of the dehydrogenase. The apoenzyme is inactive as a hydratase but recovers activity on the addition of FAD. Compared with the hydratase activity of the native enzyme, the 8-fluoro-FAD enzyme exhibits a roughly 2-fold increased activity, whereas the 5-deaza-FAD dehydrogenase is only $20 \%$ as active. A mechanism for this unanticipated secondary activity of the acyl-CoA dehydrogenase is suggested.
\end{abstract}

Theser he medium-chain (or general) acyl-CoA ${ }^{1}$ dehydrogenase catalyzes the $\alpha, \beta$-unsaturation of acyl-CoA thio esters with concomitant reduction of enzyme-bound FAD (Beinert, 1963). With preferred substrates, such as octanoyl-CoA, the product trans-2-octenoyl-CoA is bound very tightly to the reduced enzyme (Steyn-Parve \& Beinert, 1958; Thorpe et al., 1981):

E.FAD-octanoyl-CoA $\rightleftharpoons \mathrm{E} \cdot \mathrm{FAD}_{2 e} \cdot$ octenoyl-CoA

This complex is then reoxidized in two one-electron steps by electron-transferring flavoprotein (Hall \& Lambeth, 1980; Reinsch et al., 1980; Gorelick et al., 1985) in an ordered mechanism in which enoyl-CoA product dissociates from the oxidized enzyme (McKean et al., 1979). In the second step of mitochondrial $\beta$-oxidation, these thio esters are hydrated by enoyl-CoA hydratases to their L-3-(OH)-acyl-CoA derivatives (Stern et al., 1956; Wakil \& Mahler, 1954; Wakil, 1956). They are then oxidized to their corresponding 3-keto derivatives by $3-(\mathrm{OH})$-acyl-CoA dehydrogenases and finally cleaved to yield acetyl-CoA and a shortened acyl-CoA by 3-ketoacyl-CoA thiolases.

This paper demonstrates that pig kidney medium-chain acyl-CoA dehydrogenase, when freed of significant contaminating hydratase activities, retains an intrinsic short-chain enoyl-CoA hydratase (crotonase) activity:

crotonyl-CoA $+\mathrm{H}_{2} \mathrm{O} \rightleftharpoons$ L-3-(OH)-butyryl-CoA

\footnotetext{
${ }^{\dagger}$ This work was supported in part by grants from the U.S. Public Health Service (GM 26643 to C.T.) and from the Deutsche Forschungsgemeinschaft (Gh 2/4-4 to S.G.).

${ }^{\ddagger}$ University of Delaware.

Universität Konstanz.
}

A characterization of this unanticipated secondary activity of the oxidized dehydrogenase is presented.

\section{Experimental Procedures}

\section{Materials}

Crotonyl-CoA, octanoyl-CoA (lithium salt), and CoASH were obtained from P-L Biochemicals. trans-2-Octenoic acid and 2-octynoic acid were from Pfaltz \& Bauer, and trans-2hexadecenoic acid was purchased from ICN Pharmaceuticals Inc. FAD, $\mathrm{NAD}^{+}$, bovine serum albumin (fatty acid free), bovine liver crotonase, and 3-hydroxyacyl-CoA dehydrogenase were from Sigma. Octyl-Sepharose CL-4B, protein A-Sepharose CL-4B, and Sephacryl S-200 were from Pharmacia. FAD analogues were prepared as described previously (Thorpe \& Massey, 1983). 8-Chlororiboflavin was a generous gift of Dr. John Lambooy, University of Maryland. The remaining riboflavin derivatives were generous gifts from Dr. Vincent Massey, University of Michigan.

\section{Methods}

General. Visible and UV spectra were recorded on Varian 219 and Perkin-Elmer 552 spectrophotometers. NMR spectra were recorded on a Bruker Aspect 3000 250-MHz spectrometer. Unless otherwise stated, all buffers contained $0.3 \mathrm{mM}$

\footnotetext{
${ }^{1}$ Abbreviations: acyl-CoA, acyl coenzyme A; HPLC, high-pressure liquid chromatography; $\mathrm{FAD}$, flavin adenine dinucleotide; $\mathrm{NAD}^{+}$, nicotinamide adenine dinucleotide; EDTA, ethylenediaminetetraacetic acid; Tris- $\mathrm{HCl}$, tris(hydroxymethyl)aminomethane hydrochloride; PCMB, p-(chloromercuri)benzoate.
} 
EDTA. The extinction coefficients used to calculate holo- and apoenzyme concentrations are as described previously (Thorpe \& Massey, 1983). Antibodies directed against pig kidney general acyl-CoA dehydrogenase were obtained by injection of $1 \mathrm{mg}$ of dehydrogenase (after the octyl-Sepharose step, see below) in complete Freund's adjuvant into a rabbit ( $\mathrm{CH}$, bb Chincilla obtained from Thomae, Biberach, FRG). The rabbit was boosted after 4 weeks with $200 \mu \mathrm{g}$ of dehydrogenase in incomplete Freund's adjuvant. Enzyme-linked immunosorbent assays were performed according to the method of Engvall and Perlmann (1972). A strong response was obtained with the dehydrogenase; however, a minor cross-reactivity was observed when pig kidney crotonase was used. This enzyme was isolated by a modification of the procedure for pig heart crotonase (Fong \& Schulz, 1977; Ghisla and Buettner, unpublished results).

Preparation and Purification of CoA Thio Esters. Thio esters were prepared by using the mixed anhydride method of Bernert and Sprecher (1977). trans-2-octenoyl-CoA and 2-octynoyl-CoA (Freund et al., 1985) were purified on DEAE-cellulose, using a $\mathrm{LiCl}$ gradient in $1 \mathrm{mM} \mathrm{HCl}$ (Lau et al., 1977), followed by desalting on Bio-Gel P-2. trans-2hexadecenoyl-CoA was dissolved in $0.7 \mathrm{M} \mathrm{LiCl}$ and purified by hydrophobic interaction chromatography using octyl-Sepharose (Merrill et al., 1983) in a decreasing gradient from $0.7 \mathrm{M} \mathrm{LiCl}$ to water. (Methylenecyclopropyl)acetyl-CoA was prepared as described by Wenz et al. (1981) and purified by HPLC on a $\mathrm{C}_{18}$ reverse-phase column using $25 \% \mathrm{MeOH}$ in $0.02 \mathrm{M}$ sodium phosphate buffer, $\mathrm{pH}$ 6.0. Thio esters were stored as lyophilized powders.

Enzyme Purification. Pig kidney medium-chain acyl-CoA dehydrogenase was purified by the method of Gorelick et al. (1982), except that the last chromatographic step (Cibacron Blue-Sepharose) was replaced by gel filtration on Sephacryl S-200. After this step (Thorpe et al., 1979) the enzyme $(280 / 446-\mathrm{nm}$ absorbance ratio $=5.2 ; 450 \mathrm{nmol})$ in $20-50 \mathrm{~mL}$ of $50 \mathrm{mM}$ phosphate buffer, $4^{\circ} \mathrm{C}$, was taken to $35 \%$ saturation in ammonium sulfate. This solution was then applied at a flow rate of about $20 \mathrm{~mL} / \mathrm{h}$ to a $25 \times 1 \mathrm{~cm}$ column of octyl-Sepharose $4 \mathrm{~B}$ equilibrated with the same buffer. The enzyme sticks to the top of the column as an intense yellow band. The enzyme is then eluted by using a decreasing salt gradient formed from $60 \mathrm{~mL}$ of the above solution and $175 \mathrm{~mL}$ of phosphate buffer, pH 7.6. Fractions are pooled, yielding enzyme with a $280 / 446-\mathrm{nm}$ absorbance ratio of $4.9-5.0$. The pooled fractions were concentrated by ultrafiltration, washed vs. $50 \mathrm{mM}$ phosphate buffer, $\mathrm{pH} 7.6$, and stored frozen. Sodium dodecyl sulfate-polyacrylamide gel electrophoresis showed that the enzyme is greater than $99 \%$ pure by silver staining.

Enzyme Assays. The medium-chain acyl-CoA dehydrogenase was assayed for dehydrogenase activity as described previously (Thorpe, 1981). The hydratase activity was measured at $25^{\circ} \mathrm{C}$ by using the decrease in absorbance at 280 $\mathrm{nm}\left(\Delta \epsilon=3.6 \mathrm{mM}^{-1} \mathrm{~cm}^{-1}\right)$ that ąccompanies the conversion of trans-2-enoyl-CoA thio esters to their 3-OH derivatives (Steinman \& Hill, 1975). The standard assay contained 100 $\mu \mathrm{M}$ enoyl-CoA in $0.8 \mathrm{~mL}$ of $100 \mathrm{mM}$ Tris- $\mathrm{HCl}$ buffer, $\mathrm{pH}$ 8.0 , containing $0.01 \% \mathrm{w} / \mathrm{v}$ bovine serum albumin and $0.3 \mathrm{mM}$ EDTA. After recording a base line, the assay was started by the addition of enzyme.

Identification of Hydration Reaction Product. NMR was used to follow the hydration of crotonyl-CoA: $3 \mathrm{mg}$ of crotonyl-CoA was dissolved in $0.4 \mathrm{~mL}$ of buffer (prepared by adding $5 \mathrm{mmol}$ of $\mathrm{P}_{2} \mathrm{O}_{5}$ slowly and carefully to $100 \mathrm{~mL}$ of $\mathrm{D}_{2} \mathrm{O}$
Table I: Crotonyl-CoA Hydratase Activity of Preparations of Medium-Chain Acyl-CoA Dehydrogenase from Pig Kidney

hydratase act ${ }^{a}$

\begin{tabular}{ccc} 
sample & crotonyl-CoA & octenoyl-CoA \\
\cline { 2 - 3 } treated with PCMB $^{b}$ & 0.70 & 2.3 \\
after octyl-Sepharose & 0.50 & 0.39 \\
& $0.33^{d}$ & $<0.015$
\end{tabular}

(2) sample 1 treated with PCMB ${ }^{b}$

$0.33^{d}$

chromatographyc

${ }^{a}$ Expressed as apparent turnover number in the standard assay system on the basis of enzyme FAD (see Methods). ${ }^{b} 0.5 \mathrm{mM}$ PCMB in

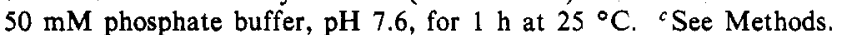
${ }^{d}$ Three different preparations gave $0.31 \pm 0.02 \mathrm{~min}^{-1}$.

and bringing to an apparent $\mathrm{pH}$ of 7.6 by the slow addition of anhydrous potassium carbonate). Prior to addition of $5 \mu \mathrm{M}$ enzyme to the NMR tube, the purified dehydrogenase was equilibrated with this buffer by ultrafiltration using Centricon microconcentrators $\left(M_{\mathrm{r}} 10000\right.$ cutoff, Amicon Corp.). After $40 \mathrm{~h}$ at $20^{\circ} \mathrm{C}$ in the dark, NMR showed that the ratio of the crotonyl-methyl doublet $(2.0 \mathrm{ppm})$ to the $3-(\mathrm{OH})$-butyrylmethyl doublet $(1.3 \mathrm{ppm})$ was $2: 1$. The solution was then ultrafiltered and the filtrate adjusted to $\mathrm{pH} 5$ with citric acid. A portion of this solution was diluted to give $110 \mu \mathrm{M}$ thio ester in $1.02 \mathrm{~mL}$ of $80 \mathrm{mM}$ Tris- $\mathrm{HCl}$ buffer, $\mathrm{pH} 8.5,25^{\circ} \mathrm{C}$, containing $2 \mathrm{mM} \mathrm{NAD}^{+}$. After a background at $340 \mathrm{~nm}$ was recorded, $10 \mu \mathrm{g}$ of 3-hydroxyacyl-CoA dehydrogenase was added. On completion of the absorbance increase, $3 \mu \mathrm{g}$ of crotonase was added and the additional production of $\mathrm{NADH}$ recorded.

HPLC Analysis. Analyses were run on a Fisher reversephase Resolvex column $(4.6 \times 250 \mathrm{~mm})$ by using an IBM LC/9533 liquid chromatograph. Samples $(10 \mu \mathrm{L})$ of the ultrafiltered stock solution at $\mathrm{pH} 5$ (see above) were injected onto the column previously equilibrated with $20 \%$ methanol $/ 80 \% 50 \mathrm{mM}$ potassium phosphate, pH 5.3 (Corkey et al., 1981). After $5 \mathrm{~min}$, at $1 \mathrm{~mL} / \mathrm{min}$, the methanol concentration was increased in a linear gradient to $70 \%$ over an additional $25 \mathrm{~min}$. In this system, 3-(OH)-butyryl-CoA elutes at $4 \mathrm{~min}$ and crotonyl-CoA at $11.5 \mathrm{~min}$. Thio esters were detected at $280 \mathrm{~nm}$ and quantitated by using extinction coefficients of 6.8 and $3.2 \mathrm{mM}^{-1} \mathrm{~cm}^{-1}$, respectively. Authentic L-3-(OH)butyryl-CoA was prepared by the addition of $50 \mu \mathrm{g}$ of crotonase to $0.7 \mathrm{~mL}$ of $4 \mathrm{mM}$ crotonyl-CoA in $30 \mathrm{mM}$ phosphate buffer, $\mathrm{pH} 7.6,25^{\circ} \mathrm{C}$. The attainment of equilibrium was followed at $305 \mathrm{~nm}$. The 3-(OH)-butyryl-CoA was purified by HPLC as described above, and the peaks from repeated injections pooled, desalted on Bio-Gel P-2, and lyophilized.

\section{RESULTS}

Initial Observations. Table I shows the apparent hydratase activity of a typical preparation of pig kidney medium-chain acyl-CoA dehydrogenase toward crotonyl- and trans-2-octenoyl-CoA. Hydratase activity was measured by following the decrease in absorbance at $280 \mathrm{~nm}$ observed upon hydration of the $\alpha, \beta$ double bond (Steinman \& Hill, 1975; see Methods). The dehydrogenase was purified as described earlier (Gorelick et al., 1982), except that the Cibacron Blue-Sepharose column was replaced by a gel filtration step (Sephacryl S-200, Table I; Thorpe et al., 1979). Various batches of enzyme prepared in this way showed considerable variation in hydratase activity while exhibiting essentially the same turnover number in the standard acyl-CoA dehydrogenase assay $\left(190 \mathrm{~min}^{-1}\right.$; Thorpe et al., 1979). This suggested the presence of a contaminating activity. However the hydratase activity shown in Table I could not simply be due to the well-known short-chain enoyl-CoA hydratase, crotonase, since this enzyme hydrates 
crotonyl-CoA about 2-4-fold more rapidly than octenoyl-CoA (Waterson \& Hill, 1972; Fong \& Schulz, 1977). In contrast, sample 1 in Table I is approximately 3 -fold more active with trans-2-octenoyl-CoA. It could be argued that the kidney short-chain hydratase has a different chain length specificity from the liver or heart enzymes. However, crotonase isolated from pig kidney shows a similar chain length preference (Buettner and Ghisla, unpublished data). A second hydratase activity optimal with medium chain lengths has been described more recently (Schulz, 1974; Fong \& Schulz, 1977), and this activity too is found in pig kidney (Buettner and Ghisla, unpublished data). Thus the activities shown in sample 1 of Table I could reflect contamination of the dehydrogenase with both short- and medium-chain hydratases.

Both the short- and long-chain enoyl-CoA hydratases are inhibited by $p$-(chloromercuri)benzoate (Stern \& del Campillo, 1956; Schulz, 1974), and thus we tested our dehydrogenase preparations with this reagent. Note that the kidney dehydrogenase is not significantly inactivated by $p$-(chloromercuri)benzoate (Thorpe et al., 1979). In the present case, using the conditions in Table I, $97 \%$ activity remained after $1 \mathrm{~h}$. This mercurial-treated enzyme retained $71 \%$ of crotonase activity but only $17 \%$ activity toward octenoyl-CoA (Table 1). These data suggested strongly that the long-chain hydratase activity was a contaminant. Accordingly, additional purification steps were tried to remove this activity. Table I shows that enzyme further purified via hydrophobic interaction chromatography on octyl-Sepharose (see Methods) exhibits very low octenoyl-CoA hydratase activity but retains appreciable activity with crotonyl-CoA. In addition, no activity with trans-2-hexadecenoyl-CoA was observed (data not shown). This purified enzyme was used for the experiments described in the following sections.

Demonstration That Crotonyl-CoA Hydration Is an Intrinsic Activity of Acyl-CoA Dehydrogenase. Crotonase has a very high turnover number with its optimal substrate, crotonyl-CoA, (340000 $\mathrm{min}^{-1}$; Waterson \& Hill, 1972), and thus it is crucial to establish that the residual hydratase activity observed with crotonyl-CoA (Table I, row 3) does not represent a trace contamination by this enzyme. It should be noted that approximately half of the activity seen with crotonyl-CoA in row 1 of Table I (before the octyl-Sepharose step) does indeed represent a crotonase impurity. However, four independent lines of evidence show that the remainder (row 3) is associated with the active site of the acyl-CoA dehydrogenase.

First, 2-octynoyl-CoA is a potent irreversible active site directed inactivator of the medium-chain acyl-CoA dehydrogenase attacking the protein, not the flavin, moiety (Freund et al., 1985). The modified enzyme is not reduced by octanoyl-CoA and apparently can no longer bind acetoacetyl-CoA, a competitive inhibitor of the native enzyme (Freund et al., 1985). In Figure 1, aliquots of the dehydrogenase were treated with increasing concentrations of 2-octynoyl-CoA, and each sample was assayed for both dehydrogenase and crotonase activity. 2-Octynoyl-CoA effects a coordinate decrease in both these activities intersecting both ordinate and abscissa close to zero (Figure 1). Control experiments showed that crotonase itself is not significantly inhibited by 2-octynoyl-CoA (using $100 \mu \mathrm{M}$ reagent in $50 \mathrm{mM}$ phosphate buffer, pH 7.6). Indeed, this acetylenic thio ester is a substrate of crotonase, being converted to 3-ketooctanoyl-CoA (Thorpe, unpublished data). A similar loss of both dehydrogenase and hydratase activities was observed when the dehydrogenase was inactivated with (methylenecyclopropyl)acetyl-CoA (Figure 1). Unlike 2-octynoyl-CoA,

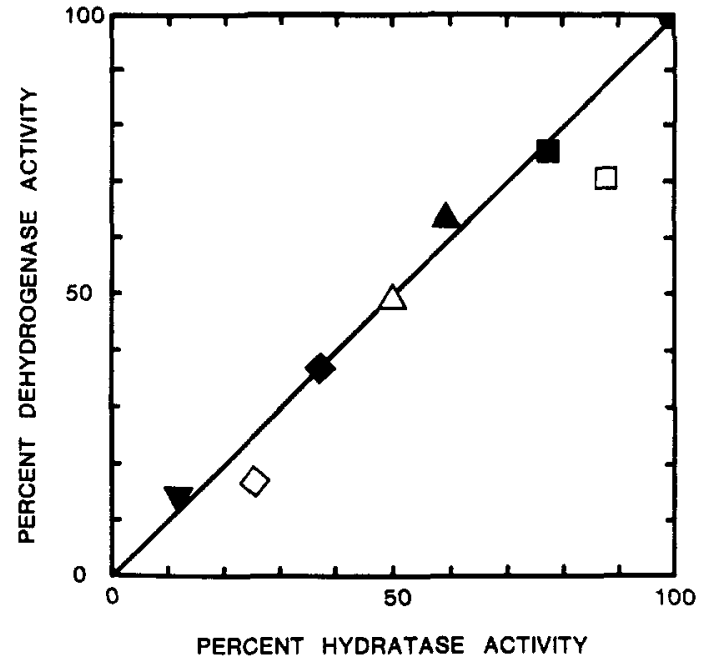

FIGURE 1: Dehydrogenase and crotonyl-CoA hydratase activities of medium-chain acyl-CoA dehydrogenase treated with increasing amounts of inhibitors. Samples of the dehydrogenase ( $90 \mu \mathrm{M}$ FAD in $50 \mathrm{mM}$ phosphate buffer, $\mathrm{pH} 7.6$ ) were treated either with $0(\bullet)$, $19(\mathbf{D}), 38(\mathbf{\Delta}), 57(\bullet)$, and $76 \mu \mathrm{M}$ 2-octynoyl-CoA ( $)$ or with 0.3 (ם), $0.5(\Delta)$ and 0.75 equiv of (methylenecyclopropyl)acetyl-CoA (O) for $1 \mathrm{~h}$ at $20^{\circ} \mathrm{C}$ and then assayed for both dehydrogenase and hydratase activities (see Methods). Activities are expressed as percentages of the untreated sample.

(methylenecyclopropyl)acetyl-CoA is a mechanism-based inactivator whose target is the flavin prosthetic group of the dehydrogenase (Wenz et al., 1981). (Methylenecyclopropyl)acetyl-CoA does not significantly inhibit crotonase under the conditions of Figure 1. The data in Figure 1 thus strongly suggest that dehydrogenase and hydratase activities reside on the same protein.

Second, it has been shown that octanoyl-CoA influences the hydratase activity. This saturated thio ester binds very tightly to medium-chain acyl-CoA dehydrogenases with reduction of enzyme FAD (Steyn-Parvê \& Beinert, 1958; Thorpe et al., 1981). If crotonyl-CoA is hydrated at the same (or an overlapping) site, severe inhibition of the hydratase activity by octanoyl-CoA would be expected. This is the case: $4.5 \mu \mathrm{M}$ octanoyl-CoA effects a greater than $98 \%$ reduction in the rate of hydration of crotonyl-CoA. Crotonase itself is not inhibited significantly under the same conditions (data not shown).

Third, the apoprotein of the medium-chain acyl-CoA dehydrogenase, prepared by a modification of the acid-ammonium sulfate precipitation procedure (Mayer \& Thorpe, 1981), is essentially inactive as a hydratase (Figure 2). Activity is recovered upon addition of FAD to the enzyme assay, as the holoenzyme is reconstituted (Figure 2, curve A). The initial slight rise in absorbance at $280 \mathrm{~nm}$ reflects the reconstitution of holoenzyme (curve B). The subsequent addition of crotonyl-CoA yields the final rate with no lag phase (curve B). An equivalent addition of FAD to crotonyl-CoA alone did not catalyze significant hydration. As expected, FAD did not accelerate the rate of crotonase-catalyzed hydration of crotonyl-CoA under the conditions used for Figure 2 (data not shown).

The fourth line of evidence comes from the use of antibodies raised against the pig kidney medium-chain length acyl-CoA dehydrogenase (see Methods). Addition of excess antibody to the dehydrogenase leads to a marginal (10\%) decrease in both dehydrogenase and hydratase activity (see Methods). Similarly, antibodies against the pig liver dehydrogenase do not inactivate this enzyme when assayed with either phenazine methosulfate or electron-transferring flavoprotein (ETF) as electron acceptors (Frerman et a1., 1980). Accordingly, the 


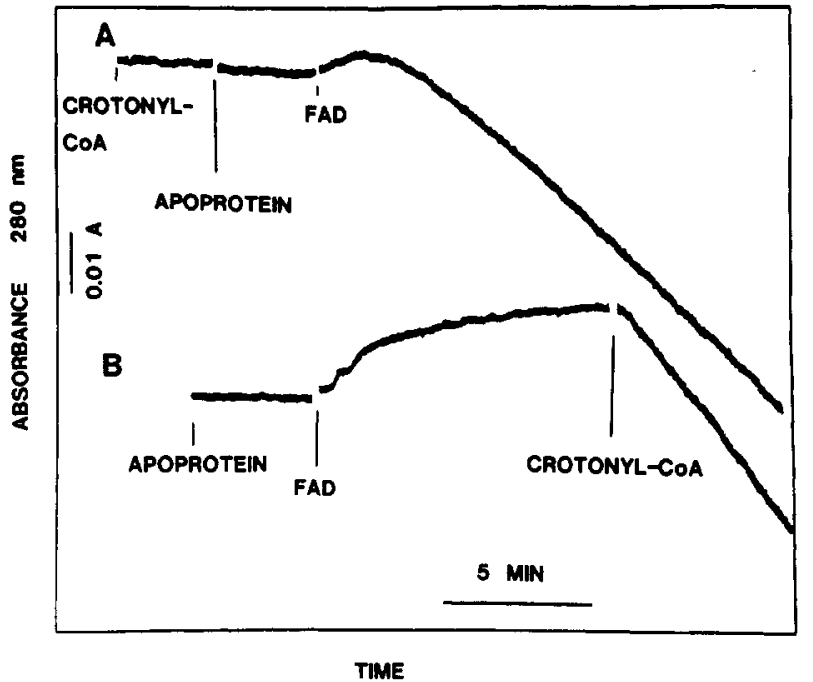

FIGURE 2: Enoyl-CoA hydratase activity of medium-chain acyl-CoA dehydrogenase requires bound FAD. The hydratase activity was determined as described under Methods, the absorbance being followed at $280 \mathrm{~nm}$. The following additions were made at the indicated times starting from the left of the figure: crotonyl- $\mathrm{CoA}(100 \mu \mathrm{M})$, apoprotein ( $4 \mu \mathrm{M}$, see Methods), and FAD $(11 \mu \mathrm{M})$. After each addition, the absorbance was brought on scale by adjustment of the zero suppression.

kidney dehydrogenase was incubated with a 1.3-fold excess of antibody and the mixture applied to a protein A-Sepharose column. Approximately $90 \%$ of the dehydrogenase activity was retained on this column. The remainder showed the same ratio of dehydrogenase to hydratase activity exhibited by the enzyme before treatment. In contrast, control experiments showed that only $10 \%$ of pig kidney crotonase (see Methods) treated with an equivalent concentration of antibody was retained by the protein A-Sepharose column.

Thus these various lines of evidence clearly indicate that the observed hydratase activity is an intrinsic property of the medium-chain acyl-CoA dehydrogenase and is not due to traces of a crotonase contaminant. This activity will now be described in more detail.

Product of the Hydratase Activity. The purified dehydrogenase was incubated with $5 \mathrm{mM}$ crotonyl- $\mathrm{CoA}$ until approximately $30 \%$ conversion to product had occurred (see Methods). The solution was ultrafiltered, and a portion of the filtrate was mixed with $\mathrm{NAD}^{+}$and 3-(OH)-acyl-CoA dehydrogenase at $\mathrm{pH} 8.5$ (see Methods). A rapid production of NADH was observed (complete in less than $1 \mathrm{~min}$ ), accounting for $25 \%$ of the total thio ester present (data not shown). Control experiments showed that the 3-(OH)-acylCoA dehydrogenase used for this experiment did not itself contain significant crotonase activity. Since this pyridine nucleotide linked dehydrogenase is specific for the $3 S(\mathrm{~L})$ enantiomer of 3-(OH)-butyryl-CoA (Lehninger \& Greville, 1953; Wakil et al., 1954), we conclude that the hydration of crotonyl-CoA by the acyl-CoA dehydrogenase also generates this stereochemistry. The subsequent addition of crotonase to the cuvette produces a further rapid increase in absorbance at $340 \mathrm{~nm}$ accounting for a additional $50 \%$ of the total thio ester concentration. The fact that only about $75 \%$ of the crotonyl-CoA is converted to acetoacetyl-CoA under these conditions presumably reflects the equilibrium constant for this $\mathrm{NAD}^{+}$-linked reaction (Wakil et al., 1954). In agreement with the previous analysis, reverse-phase HPLC showed 32\% $3-(\mathrm{OH})$-butyryl-CoA and $68 \%$ crotonyl- $\mathrm{CoA}$ in the ultrafiltrate following crotonase incubation (see Methods).

Kinetics of Hydration. The hydration of crotonyl-CoA was also examined at $\mathrm{pH}$ values of 7,8 , and 9 . Both the maximal
Table II: Hydratase Activity of Medium-Chain Acyl-CoA Dehydrogenase Substituted with FAD Analogues

\begin{tabular}{clc}
\hline FAD analogue & $E_{1}^{\circ}(\mathrm{mV})^{a}$ & $\%$ act ${ }^{8}$ \\
\hline FAD & $-208^{b}$ & 100 \\
8-Cl & $-152^{c}$ & 91 \\
$8-\mathrm{F}$ & $-180^{d}$ & 207 \\
5-deaza & $-273,^{e}-311^{f}$ & 21 \\
1-deaza & $-280^{f}$ & $<2$ \\
\hline
\end{tabular}

${ }^{a}$ Redox potentials for two-electron couples taken from the indicated references. ${ }^{6}$ Draper \& Ingraham, 1968. ' Moore et al., 1978. ${ }^{d}$ Stewart and Massey, unpublished observations. 'Stankovich \& Massey, 1976. ${ }^{f}$ Walsh et al., 1978. ${ }^{8}$ Activity determined in the standard crotonyl-CoA hydration assay (see Methods) using a final concentration of $3.5 \mu \mathrm{M}$ apoprotein (Mayer \& Thorpe, 1981) reconstituted with $\mathrm{FAD}$ or the indicated analogues $(38 \mu \mathrm{M}$ apoprotein dissolved in $150 \mathrm{~mm}$ Tris buffer, $\mathrm{pH} 8.9$, at $4^{\circ} \mathrm{C}$, incubated with a 2 -fold excess of analogue for $2 \mathrm{~h}$ ).

turnover numbers and the $K_{\mathrm{m}}$ values increase with increasing $\mathrm{pH}\left(0.14,0.36\right.$, and $0.47 \mathrm{~min}^{-1}$ and 16,20 , and $38 \mu \mathrm{M}$, respectively). Note that the activities of both the short-chain and the long-chain enoyl-CoA hydratases also increase with increasing $\mathrm{pH}$, the former showing a continuous increase over the $\mathrm{pH}$ range 5.0-9.4 (Stern \& Campillo, 1956) and the latter a sharper increase with a midpoint of 6.5 (Schulz, 1974).

Activity with Flavin Analogues. The ready reconstitution of the apoprotein of the medium-chain acyl-CoA dehydrogenase with flavin analogues (Thorpe \& Massey, 1983) allows the effect of FAD substitutions on the hydratase activity to be examined. As noted above, the prosthetic group is essential for this activity. Table II shows that the hydratase activity is dependent on the nature of the FAD analogue. Of the small number of reconstituted enzymes tested, those analogues with redox potentials more positive than FAD itself (8-chloro- and 8-fluoro-FAD) show substantial hydratase activity. Of the remainder, 5-deaza-FAD exhibits a considerable decrease in activity, while 1-deaza-FAD is essentially inactive.

\section{Discussion}

The available evidence strongly suggests that the hydratase activity of the medium-chain acyl-CoA dehydrogenase is associated with the active center employed for substrate dehydrogenation. Thus hydratase activity is inhibited by thio esters that are either active site directed inactivators (with either protein or flavin targets) or good substrates of the dehydrogenase. Further, this additional activity not only requires the presence of the flavin prosthetic group but also is influenced by modifications of the isoalloxazine ring. Hydratase activity with crotonyl-CoA is small (with a maximal turnover number some 500-1000-fold less than the $V_{\max }$ for the dehydrogenation of butyryl-CoA using electron-transferring flavoprotein as second substrate; McKean et al., 1979; Reinsch et al., 1980). Although presumably insignificant physiologically, the hydration of crotonyl-CoA becomes important in vitro when high enzyme concentrations are used and when incubations are performed for long periods. It should also be noted that the hydration of crotonyl-CoA by the dehydrogenase represents a sizable rate enhancement over the uncatalyzed reaction. In control experiments, no hydration of crotonyl-CoA was detected over several hours in the absence of enzyme.

The finding that the product of crotonyl-CoA turnover is the L-3-(OH)-butyryl-CoA isomer is consistent with the stereochemistry of substrate dehydrogenation. Biellmann and Hirth (1970a,b) and Bucklers et al. (1970) showed that oxidation of butyryl-CoA proceeds via removal of pro- $R$ hydrogens at both $\mathrm{C}-2$ and $\mathrm{C}-3$ positions. Further, recent studies 


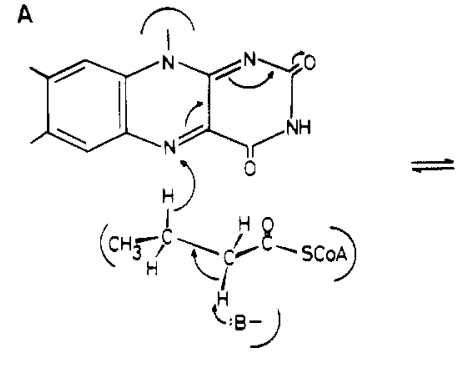<smiles>CCCN1c2cc(C)c(I)cc2Nc2c1nc([O-])[nH]c2=O</smiles>

B
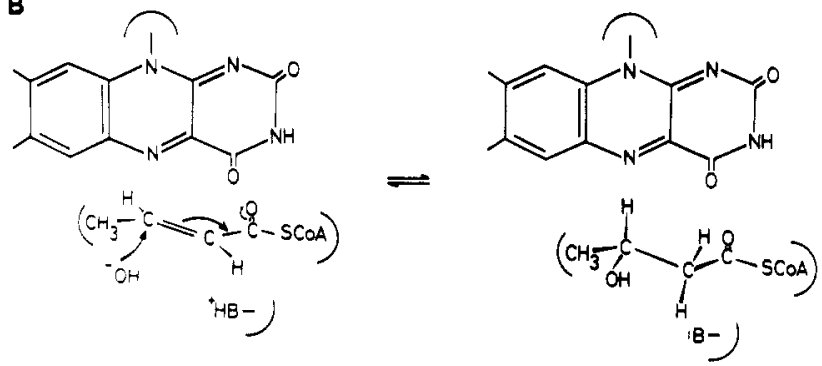

FIGURE 3: Schematic representation of the dehydrogenase (A) and hydratase activities (B) of pig kidney general acyl-CoA dehydrogenase.

with the medium-chain acyl-CoA dehydrogenase reconstituted with 5-deaza-FAD demonstrated a direct transfer of the pro- $R$ C-3 hydrogen to the 5-position of the flavin ring (Ghisla et al., 1984). Dehydrogenation is probably concerted, as shown in Figure 3, panel A (Ghisla et al., 1984; Ghisla, 1984; Rojas et al., 1985). Fendrich and Abeles (1982) have suggested that the base "B" that abstracts the pro- $R$ C-2 proton (Figure $3 \mathrm{~A}$ ) is a glutamate residue.

All of the available evidence suggests that crotonyl-CoA is hydrated at the same site as that employed for the dehydrogenation of saturated substrates. Accordingly, attack of an incoming hydroxide or water nucleophile would be expected to occur from the less hindered $r e$ face of the carbon-carbon double bond (distal to the FAD; Figure 3B), yielding the $3(S)-\mathrm{OH}$ enantiomer. This is the observed stereochemistry. The lack of significant hydration observed with trans-2-octenoyl- and trans-2-hexadecenoyl-CoA might reflect the more restricted access of water to the double bond in these more hydrophobic, tightly binding, thio esters.

With regard to the stereochemistry at C-2, it would appear reasonable that residue $B$ would also be used in the hydration reaction shown in Figure 3B. For example, the acyl-CoA dehydrogenases catalyze exchange of the pro- $R \mathrm{C}-2$ hydrogen when incubated with substrates in the absence of electron acceptors (Biellman \& Hirth, 1970a,b; Murfin, 1974; Ghisla et al., 1984; Ikeda et al., 1985). Utilization of the same residue $\mathrm{B}$ as before would lead to an overall syn addition of the elements of water across the double bond (Figure 3B). Crotonase itself catalyzes the hydration of crotonyl-CoA with this stereochemistry, yielding 3(S)-hydroxybutyryl-CoA (Willadsen \& Eggerer, 1975). syn addition of water is also observed during the hydration of methylacryloyl-CoA by an enoyl-CoA hydratase from Pseudomonas putida (Aberhart \& Tann, 1979). Willadsen and Eggerer (1975), considering several other examples of this stereochemical course, concluded that an acidic hydrogen is a necessary prerequisite for syn addition. In the present case, the developing carbanion at $\mathrm{C}-2$ could be stabilized as an enolate prior to protonation (Figure $3 \mathrm{~B}$ ). Further, such a carbanion might gain stabilization via charge transfer (Massey \& Ghisla, 1974) with electron-deficient flavin analogues and conversely be destabilized upon replacement of the normal FAD by derivatives with more negative redox potentials (see Table II). A thorough study utilizing a large number of FAD analogues will be required to test this intriguing hypothesis.

\section{AdDED IN PROOF}

Ellison and Engel have recently shown that the bacterial butyryl-CoA dehydrogenase from Megasphaera elsdenii has intrinsic crotonase activity (Ellison \& Engel, 1986; Ellison and Engel, personal communication).

Registry No. FAD, 146-14-5; crotonyl-CoA, 992-67-6; 2-octynoyl-CoA, 96448-59-8; (methylenecyclopropyl)acetyl-CoA, 5689843-2; octanoyl-CoA, 1264-52-4; medium-chain acyl coenzyme A dehydrogenase, 74506-38-0; enoyl coenzyme A hydratase, 9027-13-8.

\section{REFERENCES}

Aberhart, D. J., \& Tann, C.-H. (1979) J. Chem. Soc., Perkin Trans. 1, 939-942.

Beinert, H. (1963) Enzymes, 2nd Ed. 7, 447-466.

Bernert, J. T., \& Sprecher, H. (1977) J. Biol. Chem. 252, 6736-6744.

Biellmann, J. F., \& Hirth, C. G. (1970a) FEBS Lett. 9, 55-56.

Biellmann, J. F., \& Hirth, C. G. (1970b) FEBS Lett. 9, 335-336.

Bucklers, L., Umani-Ronchi, A., Rétey, J., \& Arigoni, D. (1970) Experientia 26, 931-933.

Corkey, B. E., Brandt, M., Williams, R. J., \& Williamson, J. R. (1981) Anal. Biochem. 118, 30-41.

Draper, R. D., \& Ingraham, L. L. (1968) Arch. Biochem. Biophys. 125, 802-808.

Ellison, P. A., \& Engel, P. C. (1986) Biochem. Soc. Trans. 14, 158.

Engvall, E., \& Perlmann, P. (1972) J. Immunol. 109, 129-135.

Fendrich, G., \& Abeles, R. H. (1982) Biochemistry 21, 6685-6695.

Fong, J. C., \& Schulz, H. (1977) J. Biol. Chem. 252, 542-547.

Frerman, F. E., Kim, J.-J., Huhta, K., \& McKean, M. C. (1980) J. Biol. Chem. 255, 2195-2198.

Freund, K., Mizzer, J. P., \& Thorpe, C. (1984) in Flavins and Flavoproteins (Bray, R. C., Engel, P. C., \& Mayhew, S. G., eds.) pp 443-446, de Gruyter, Berlin.

Freund, K., Mizzer, J. P., Dick, W., \& Thorpe, C. (1985) Biochemistry 24, 5996-6002.

Ghisla, S. (1984) in Flavins and Flavoproteins (Bray, R. C., Engel, P. C., \& Mayhew, S. G., Eds.) pp 385-401, de Gruyter, New York.

Ghisla, S., Thorpe, C., \& Massey, V. (1984) Biochemistry 23, 3154-3160.

Goding, J. W. (1978) J. Immunol. Methods 39, 258-308.

Gorelick, R. J., Mizzer, J. P., \& Thorpe, C. (1982) Biochemistry 21, 6936-6942.

Gorelick, R. J., Schopfer, L. M., Ballou, D. P., Massey, V., \& Thorpe, C. (1985) Biochemistry 24, 6830-6839.

Hall, C. L., \& Lambeth, J. D. (1980) J. Biol. Chem. 255 , 3591-3595.

Ikeda, Y., Hine, D. G., Okamura-Ikeda, K., \& Tanaka, K. (1985) J. Biol. Chem. 260, 1326-1337.

Lau, E. P., Haley, B. E., \& Barden, R. E. (1977) Biochemistry 16, 2581-2585.

Lehninger, A. L., \& Greville, G. D. (1953) Biochim. Biophys. Acta 12, 188-202.

Massey, V., \& Ghisla, S. (1974) Ann. N.Y. Acad. Sci. 227, 446-465.

Mayer, E. J., \& Thorpe, C. (1981) Anal. Biochem. 116, 227-229. 
McKean, M. C., Frerman, F. E., \& Mielke, D. M. (1979) J. Biol. Chem. 254, 2730-2735.

Merrill, A. H., Gidwitz, S., \& Bell, R. M. (1982) J. Lipid Res. 23, 1368-1372.

Moore, E. G., Cardemil, E., \& Massey, V. (1978) J. Biol. Chem. 253, 6413-6422.

Moore, E. G., Ghisla, S., \& Massey, V. (1979) J. Biol. Chem. 254, 8173-8178.

Murfin, W. W. (1974) Ph.D. Thesis, Washington University, St. Louis, MO.

Reinsch, J. W., Feinberg, B. A., \& McFarland, J. T. (1980) Biochem. Biophys. Res. Commun. 94, 1409-1416.

Rojas, C., Schmidt, J., Lee, M.-Y., Gustafson, W. G., \& McFarland, J. T. (1985) Biochemistry 24, 2947-2954.

Schulz, H. (1974) J. Biol. Chem. 249, 2704-2709.

Stankovich, M. T., \& Massey, V. (1976) Biochim. Biophys. Acta 452, 335-344.

Steinman, H. M., \& Hill, R. L. (1975) Methods Enzymol. 35, 136-151.

Stern, J. R. (1961) Enzymes, 2nd Ed. 5, 511-529.

Stern, J. R., \& del Campillo, A. (1956) J. Biol. Chem. 218, 985-1002.

Stern, J. R., del Campillo, A., \& Raw, I. (1956) J. Biol. Chem. 218, 971-983.
Steyn-Parvê, E. P., \& Beinert, H. (1958) J. Biol. Chem. 233, 843-852.

Thorpe, C. (1981) Methods Enzymol. 71, 366-374.

Thorpe, C., \& Massey, V. (1983) Biochemistry 22, 2972-2978.

Thorpe, C., Matthews, R. G., \& Williams, C. H. (1979) Biochemistry 18, 331-337.

Thorpe, C., Ciardelli, T. L., Stewart, C. J., \& Wieland, Th. (1981) Eur. J. Biochem. 118, 279-282.

Wakil, S. (1956) Biochim. Biophys. Acta 19, 497-504.

Wakil, S., \& Mahler, H. R. (1954) J. Biol. Chem. 207, 125-132.

Wakil, S. J., Green, D. E., Mii, S., \& Mahler, H. R. (1954) J. Biol. Chem. 207, 631.

Walsh, C., Fisher, J., Spencer, R., Graham, D. W., Ashton, W. T., Brown, J. E., Brown, R. D., \& Rogers, E. F. (1978) Biochemistry 17, 1942-1951.

Waterson, R. M., \& Hill, R. L. (1972) J. Biol. Chem. 247, 5258-5265.

Wenz, A., Thorpe, C., \& Ghisla, S. (1981) J. Biol. Chem. 256, 9809-9812.

Willadsen, P., \& Eggerer, H. (1975) Eur. J. Biochem. 54, 247-252. 